\title{
Quantification of myocardial viability in diffuse and contiguous infarction using 3D inversion recovery MRI: Validation against microscopy
}

\author{
Robert Jablonowski*, Mark W Wilson, Noor Joudi, Maythem Saeed \\ From 17th Annual SCMR Scientific Sessions \\ New Orleans, LA, USA. 16-19 January 2014
}

\section{Background}

Sheifer et al indicated that undetected infarction account for at least $20 \%$ of all infarctions and carry a prognosis as poor as detected ones [1]. Large myocardial infarction has been measured using both 3D and 2D delayed enhancement MRI, which was compared with histochemical staining [2]. The purpose of this MRI study was to 1) measure diffuse and large infarction size using delayed contrast enhanced 3D inversion recovery (IR) gradient echo (GRE) in beating and non-beating swine hearts and 2) compare the 3D measurements against 2D-IR GRE, histochemical staining and microscopic histopathology.

\section{Methods}

Pigs were subjected to: 1 ) diffuse infarction by infusing $32 \mathrm{~mm}^{3}$ microemboli in the LAD (group I, $\mathrm{n}=7$ ), 2) large infarction by occluding LAD for 90 min (group II, $\mathrm{n}=7$ ) or 3) combined large and diffuse infarction by occluding LAD for $90 \mathrm{~min}$ and infusion of $32 \mathrm{~mm}^{3}$ microemboli (group III, $\mathrm{n}=7$ ). Three days following coronary intervention, contrast enhanced 3D $(\mathrm{TE} / \mathrm{TR} / \mathrm{TI}=2.3 / 4.8 / 230-240 \mathrm{~ms})$ and $2 \mathrm{D}$ $(\mathrm{TE} / \mathrm{TR} / \mathrm{TI}=1.8 / 6.8 / 230-240 \mathrm{~ms})$ was performed for measuring myocardial infarction in beating hearts. The animals were then euthanized inside the scanner and reimaged using the same imaging sequences. At postmortem, histochemical triphenyltetrazolium chloride (TTC) and microscopic histopathology (hematoxylin-eosin) stains were used for validation.

\section{Results}

There was no significant difference in infarction size between delayed contrast enhanced 3D and 2D MRI in both beating and non-beating hearts (Table 1). Furthermore, theses sequences demonstrated the gradients in infarction size as a function of insult severity. In beating hearts close correlations and agreements were found

Table 1 Comparison between 2D, 3D-LGE MRI, histochemical staining and histopathological infarct size.

\begin{tabular}{|c|c|c|c|c|}
\hline & 3D-IR GRE & 2D-IR GRE & TTC & Microscopy \\
\hline \multicolumn{5}{|c|}{ Beating heart } \\
\hline Group I & $9.0 \pm 0.6$ & $9.0 \pm 0.3$ & & \\
\hline Group II & $14.4 \pm 0.6^{*+}$ & $14.3 \pm 0.5^{*+}$ & & \\
\hline Group III & $16.0 \pm 1.8^{*}$ & $15.8 \pm 1.6^{*}$ & & \\
\hline \multicolumn{5}{|c|}{ Non-beating heart } \\
\hline Group I & $9.0 \pm 0.4$ & $9.2 \pm 0.7$ & $8.4 \pm 0.4$ & \\
\hline Group ॥ & $14.6 \pm 0.6^{*}$ & $14.1 \pm 0.5^{*}$ & $14.9 \pm 1.8^{*}$ & $13.3 \pm 0.5$ \\
\hline Group III & $16.1 \pm 1.9^{*}$ & $16.1 \pm 2.1^{*}$ & $16.0 \pm 1.6^{*}$ & $17.8 \pm 1.8^{\# \$}$ \\
\hline
\end{tabular}

${ }^{*} p<0.05$ compared with group I, ${ }^{*} p<0.05$ compared with coherent $3 \mathrm{D}$ and $2 \mathrm{D},{ }^{; 5} \mathrm{p}<0.05$ compared with group II, i+ $p<0.05$ compared with microscopy of the same cohort.

\footnotetext{
Department of Radiology and Biomedical Imaging, School of Medicine,
} University of California San Francisco, San Francisco, California, USA 


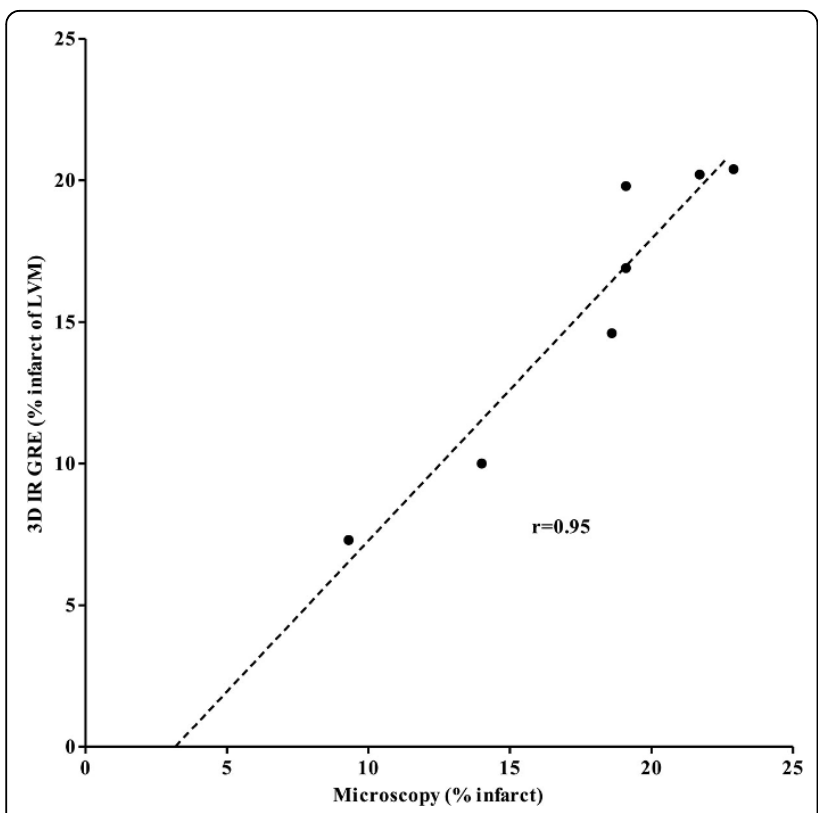

Figure 1 Correlation between myocardial infarction measured on 3D MRI in beating hearts and microscopy $(y=1.1 \times-3.5)$.

between infarction size measured on $3 \mathrm{D}$ and $2 \mathrm{D}$ MRI $(\mathrm{r}=0.81-0.95$ for all groups, bias: group $\mathrm{I}=0.033 \pm$ $1.2 \%$, group II $=0.13 \pm 1.2 \%$, group III $=-0.17 \pm 1.8 \%$ ). Acute large infarction was overestimated on $3 \mathrm{D}$ and $2 \mathrm{D}$ MRI in beating hearts compared with microscopy due to the inclusion of edematous border zone. Figure 1 demonstrates a close correlation between 3D MRI in beating hearts and microscopy of combined large and diffuse infarction (group III), but 3D MRI underestimated true myocardial infarction size (bias: $-2.2 \pm 1.6 \%$ ) due to the inherent limited spatial resolution and the small islands of necrosis in the area at risk.

\section{Conclusions}

Myocardial infarction measured on 3D MRI is highly correlated and in a good agreement with infarction measured microscopically. This imaging sequence has the potential to measure diffuse and large acute myocardial infarction and has minimal motion artefacts.

\section{Funding}

N/A.

Published: 16 January 2014

\section{References}

1. Scheifer SE, et al: Ann Internal Med 2001, 135:801-811.

2. Dewey M, et al: Radiology 2006, 239:703-709.
doi:10.1186/1532-429X-16-S1-P80

Cite this article as: Jablonowski et al:: Quantification of myocardial viability in diffuse and contiguous infarction using 3D inversion recovery MRI: Validation against microscopy. Journal of Cardiovascular Magnetic Resonance 2014 16(Suppl 1):P80.
Submit your next manuscript to BioMed Central and take full advantage of:

- Convenient online submission

- Thorough peer review

- No space constraints or color figure charges

- Immediate publication on acceptance

- Inclusion in PubMed, CAS, Scopus and Google Scholar

- Research which is freely available for redistribution

Submit your manuscript at www.biomedcentral.com/submit 